OPEN ACCESS

Edited by:

Sonia Yeh,

Chalmers University of Technology,

Sweden

Reviewed by:

Phil Renforth,

Cardiff University, United Kingdom

Tobias Proell,

Universität für Bodenkultur Wien,

Austria

David Daniels,

United States Energy Information Administration, United States

Jennifer Wilcox,

Colorado School of Mines,

United States

*Correspondence:

Adriano Vinca

vinca@iiasa.ac.at

Specialty section: This article was submitted to Energy Systems and Policy, a section of the journal

Frontiers in Energy Research

Received: 09 February 2018

Accepted: 24 April 2018

Published: 15 May 2018

Citation:

Vinca A, Emmerling $J$ and Tavoni $M$ (2018) Bearing the Cost of Stored

Carbon Leakage.

Front. Energy Res. 6:40.

doi: 10.3389/fenrg.2018.00040

\section{Bearing the Cost of Stored Carbon Leakage}

\author{
Adriano Vinca ${ }^{1,2 *}$, Johannes Emmerling ${ }^{1,3}$ and Massimo Tavoni ${ }^{1,3,4}$ \\ ${ }^{1}$ Fondazione Eni Enrico Mattei, Milan, Italy, ${ }^{2}$ International Institute for Applied System Analysis, Laxenburg, Austria, \\ ${ }^{3}$ Centro-Euro Mediterraneo per i Cambiamenti Climatici, Milan, Italy, ${ }^{4}$ Politecnico di Milano, Milan, Italy
}

Carbon capture and sequestration (CCS) is considered a key technology for stabilizing climate change. However, leakage of $\mathrm{CO}_{2}$ from stored carbon can potentially undermine the value of carbon storage as a mitigation option. Thus, monitoring and verifiability of $\mathrm{CO}_{2}$ storage should be encouraged through policy provisions such as accounting and pricing of leaked emissions. Here we assess different institutional and economic mechanisms for accounting for carbon leakage. Using an integrated assessment model we quantify the impacts on the climate, the economy and the mitigation strategies. Results show that carbon leakage can reduce the share of fossil based CCS by up to $35 \%$, if it is controlled and correctly priced. Biomass based CCS is less affected. Accounting for leakage leads to an increase of climate policy costs of up to 0.4 percentage points due to increased emissions.

Keywords: carbon leakage, $\mathrm{CCS}, \mathrm{CO}_{2}$ geological storage, integrated assessment model, climate mitigation

\section{HIGHLIGHTS}

- Carbon leakage from CCS can lead to up to $25 \mathrm{GtCO}_{2}$ of additional emissions throughout the twenty-first century for a leakage rate of $0.1 \%$ per year.

- CCS deployment is lowered, by as much as 30\% (Fossil) and 10\% (BECCS), when leakage is taken into account.

- Carbon prices increase by around 5 per cent. Overall policy costs increase by about $0.2-0.4$ percentage points.

- If not taken into consideration nor priced, leakage contributes to an additional 0.01-0.02 degrees of temperature increase.

- China, Latin America, the U.S., and Canada have the highest expected leakage.

\section{INTRODUCTION}

The increasing awareness of possibly irreversible damages of global warming has pushed both public opinion and governments toward the support of increasingly stringent climate mitigation measures. However, the path toward climate change policies is correlated to both technological and economic challenges (IPCC, 2014). Among typical mitigation strategies, Carbon Capture and Storage (CCS) and Carbon Dioxide Removal (CDR) represent valuable alternatives to renewable energy sources. According to existing studies IPCC (2014), the CCS potential will have an important role in reducing the carbon intensity of electricity. CCS might thus represent a considerable share 
of emission reduction in the energy sector (Metz et al., 2005; Finkenrath, 2011; NAS, 2015; GCCSI, 2016).

CCS and CDR can also help reduce the costs of mitigation. Nonetheless, their development has not been as fast as expected in the last decades (Davidson et al., 2017). This low deployment can be associated with the absence of adequate incentives, lack of public acceptance, and to technological uncertainties associated with CCS (IEA, 2016; Lipponen et al., 2017). Among these barriers, carbon leakage from stored $\mathrm{CO}_{2}$ could counteract the usefulness of carbon sequestration to help limiting global temperature increase (van der Zwaan and Smekens, 2009). In this paper, we analyze the impact of $\mathrm{CO}_{2}$ leakage on the propsects of CCS in the power sector and the economic costs of mitigation ${ }^{1}$.

We evaluate different policy provisions to help take leakage into account. Several problems can arise with leakage. Estimating its size is difficult and costly, since monitoring techniques have focused on small scale case studies so far (Romanak et al., 2012; Dethlefsen et al., 2013). A second source of uncertainty is related to the economic liability of leaked emissions (Wilson et al., 2003; Imbus et al., 2013). Finally, leakage might depend on the stringency of the climate policy. To address these questions, we use an integrated assessment model to examine three main dimensions: climate targets, leakage rates and policy provisions to counteract it. We consider the 2 and $1.5^{\circ} \mathrm{C}$ temperature increase targets by 2100 , a range of possible leakage rates consistent with the literature, and different cases of pricing and liability of carbon leakage in the atmosphere. On this last point, we analyze whether leaked $\mathrm{CO}_{2}$ is (a) not monitored nor taken into account in the carbon budget, (b) taken into account for the chosen carbon budget, but not priced at the carbon price, e.g., due to institutional or technological constraints, or (c) taken into account in the carbon budget and priced at the carbon price. These three cases allow us to disentangle the importance of monitoring and pricing leaked emissions.

\section{BACKGROUND INFORMATION}

\section{1. $\mathrm{CO}_{2}$ Transportation and Storage}

Carbon dioxide, once removed from the exhaust gases of a power plant, can be re-used for industry purposes or stored (GCCSI, 2011). Capture, transportation, and storage or use each require the construction and maintenance of additional infrastructure, along with associated costs (Metz et al., 2005; GCCSI, 2011; Benson et al., 2012). After storage, transporting $\mathrm{CO}_{2}$ to storage or use sites is the next important cost component. Although transportation through pipelines of dense supercritical $\mathrm{CO}_{2}$ appears to be the most convenient technology for inland transport, other options, including shipping, are conceivable for particular cases (e.g., remote offshore distances) (Cole et al., 2011; ZEP, 2011). The costs for pipeline transportation comprise both capital costs (e.g., pipeline construction, pipe coating, protection systems) and operations costs (e.g., surveillance, maintenance, expert supervision) (McCoy and Rubin, 2008).

\footnotetext{
${ }^{1}$ Note that we therefore do not consider direct air capture (DAC) or other CDR options, which face additional technical and other uncertainties.
}

When it comes to the options for carbon storage, here we focus on geological storage, which comprises several different storage options under ground. Among the different storage options, only a few are considered reliable for large scale injections: underground saline aquifers, depleted or expiring oil and gas fields, and coal beds. Deep saline aquifers are geological formations of porous rocks, permeable and saturated with water, that allow the withdrawal of non-potable water (IEAGHG, 2008). Also oil and gas fields where extraction is declining are interesting options for $\mathrm{CO}_{2}$ storage. Enhanced oil recovery (EOR) consist of injecting $\mathrm{CO}_{2}$ in declining oil fields to boost oil extraction due to fluid pressure. Being an economically convenient technique, it has already been used in the U.S. for many decades. However, traditional EOR was not intended to maximize carbon storage, and the amount of $\mathrm{CO}_{2}$ trapped has always been relatively low (Godec et al., 2011; IEA, 2015). Depleted oil or gas fields can be reliable storage sites, as they have naturally stored natural gas for thousands of years and have been geologically fully characterized. Coal seams that are uneconomic to mine may still contain methane trapped in coal pores, which may be released via Enhanced Coal Bed Methane (ECBM) recovery (IEA-ETSAP, 2010). Similar to EOR, ECBM consists of injecting $\mathrm{CO}_{2}$ into the the coal bed, some of which displaces the $\mathrm{CH}_{4}$ and remains sequestered in its place. Other potential $\mathrm{CO}_{2}$ storage options, such as $\mathrm{CO}_{2}$ mineralization or deep ocean storage, although considered important potential future storage options by some sources (Sanna et al., 2014; Romanov et al., 2015), are excluded from the current study due to their high current and uncertain future costs, public acceptance issues, and uncertain impacts on ecosystems (IEA, 2008).

Since estimating global or regional available storage capacity requires extensive investigation of vast geological areas and the use of advanced measurement processes, the uncertainty on available capacity is still high. Dooley (2013) considers a theoretical global capacity of $35,300 \mathrm{GtCO}_{2}$, which is reduced to an effective and then practical potential of 13,500 and 3,900 $G t \mathrm{CO}_{2}$, respectively. In the IEAGHG $(2011,2016)$ reports, an average global availability of $11,152 \mathrm{GtCO}_{2}$ is estimated, which is an order of magnitude that is accepted also by other authors (Hendriks et al., 2004; Koelbl et al., 2014).

With regard to the geological storage costs, the variability in the literature is even higher, since many studies describe specific sites, which can have different properties one from another, such as the storage type, regional geology, and pre-built infrastructure. For example, Rubin et al. (2015) estimates a cost range of between 1 and $18 \$ / t \mathrm{CO}_{2}$. Similar values are reported in IEAGHG (2011) and ZEP $(2011)^{2}$. Concerning ECBM and EOR storage options, the estimated costs range from negative to high positive values, depending on whether the process is used to boost gas or oil extraction, or to optimize $\mathrm{CO}_{2}$ storage (Gale, 2004; Koelbl et al., 2013, 2014).

\subsection{Carbon Leakage}

With the term leakage, or seepage, we refer to undesired $\mathrm{CO}_{2}$ losses to the atmosphere due to infrastructure or

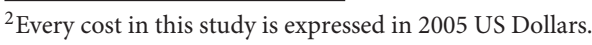


storage malfunctions. Leakage could occur during $\mathrm{CO}_{2}$ transportation, underground injection, or after storage. Leakage from transportation is due to pipeline losses, but can be considered unlikely due to pipeline monitoring systems that measure pressure losses (GCCSI, 2014). The injection process can also lead to unwanted $\mathrm{CO}_{2}$ leakage: injection requires a wellbore, a conduit where upward flows are possible. Finally, undesired loss of $\mathrm{CO}_{2}$ from storage sites can occur due to imperfect storage sealing. Pipeline and injection losses are referred to as instantaneous leakage, as they take place at the same time period of capture and before the $\mathrm{CO}_{2}$ is stored. On the contrary, seepage from storage sites is delayed in time, meaning that $\mathrm{CO}_{2}$ can also leak from under ground several years after being captured. In this case, leakage is related to the cumulative quantity of $\mathrm{CO}_{2}$ that has been stored in the past. This aspect is critical as one of the main issues related to CCS deployment is the long term suitability of storage options (Metz et al., 2005; van der Zwaan and Gerlagh, 2009b). Moreover, there is still high uncertainty about the true reliability of storage sites. As the long term response of storage sites could hinder CCS effectiveness as a mitigation option, we focus our attention on storage leakage.

The damages that leakage might cause can be distinguished between local and global (Wilson et al., 2003). From the local point of view, meaning a few kilometers around the storage site, concentrated $\mathrm{CO}_{2}$ leakage could be harmful for people and livestock. Another problem caused by $\mathrm{CO}_{2}$ losses is ground water contamination. Seepage could reach groundwater aquifers, rather than reaching directly the atmosphere surface (Bielicki et al., 2015; Deng et al., 2017). This would lower the aquifer water $\mathrm{pH}$ and could lead to the release of harmful metals, an effect known as acidification (Little and Jackson, 2010). Alternatively, acidification might also occur during the injection in saline aquifers, degrading the well cements (Celia et al., 2015). These local issues might raise discussions on storage management and public acceptance, however they have less consequences at a global level. By contrary, this article focuses on $\mathrm{CO}_{2}$ leakage into the atmosphere as a global issue that contributes to global warming. In particular, the prospect of leakage could hinder the mitigation potential of fossil fuel CCS, hampering its future deployment. Consequently, it would lead to an increase in climate policy costs (van der Zwaan and Smekens, 2009). For this reason it is important to understand the magnitude of leakage, which is captured typically through the leakage rate, that is, the rate at which $\mathrm{CO}_{2}$ leakage occurs at a specific storage site per year in terms of the stored carbon.

Bielicki et al. (2015) summarizes results on percentage of stored emissions from the storage sites, with different levels of permeability and compares the results with the U.S. Department of Energy aim of not more than $1 \%$ leaked $\mathrm{CO}_{2}$ in total (Bielicki et al., 2016). Assuming a pessimistic estimate of rock permeability equal to $10^{-10} \mathrm{~m}^{2}, 10 \%$ of stored volumes are expected to leak within 30 years, with permeability of $10^{-12} \mathrm{~m}^{2}$, the leaked emissions decrease to about $0.1 \%$ during the same period. However, an evaluation of leaked quantities over larger time horizons like 100 or 1,000 years, which are the time frames usually considered by institutions like the DOE or IPCC, is still missing. According to Bielicki et al. (2015) only the case with
$10^{-12} \mathrm{~m}^{2}$ permeability would conform to the storage permanence goal of $1 \%$ leakage. These permeability assumptions have been tested in the GCAM model by Deng et al. (2017), obtaining leakage over the twenty-first century of between $\sim 0.003$ and $\sim 0.2 \%{ }^{3}$. Another finding is that with a low injection rate, leakages are higher at the beginning, while in the long term this might change. The behavior of leakage rates could therefore depend also on time: in particular, the percentage of $\mathrm{CO}_{2}$ lost with respect to the total stored amount could exponentially decay or show an S-shaped behavior. These complex paths try to replicate some important geological and fluid-dynamic aspects of $\mathrm{CO}_{2}$ leakage. For example, the exponentially decaying curve stands for a storage site where $\mathrm{CO}_{2}$ leaks at first easily, then increasingly more scarcely due to the fact that only the best trapped $\mathrm{CO}_{2}$ remains in the storage site. An S-shaped curve would represent the $\mathrm{CO}_{2}$ leaking through multiple layers of media (van der Zwaan and Gerlagh, 2009a,b). However, as in van der Zwaan and Smekens (2009), leakage rate could be also reasonably well approximated as a constant percentage of the cumulative stored quantity within each storage site. Summing up, according to the IPCC (Metz et al., 2005), storage sites are probably reliable and safe, meaning they release very low or practically zero leakages. van der Zwaan and Smekens (2009) suggest a maximum acceptable value for the leakage rate below $0.5 \%$ per year, while for Bielicki et al. (2015) lower leakage rates are conceivable. In this study we therefore consider the maximum leakage rate of $0.1 \%$ per year, which implies leakage of $9.5 \%$ over a century, while a more reasonable leakage rate that we test is $0.01 \% /$ year, which leads to a theoretical leakage of $1 \%$ of injected $\mathrm{CO}_{2}$ over 100 years ${ }^{4}$.

As leakage remains uncertain, it is of vital importance to ensure effective and reliable monitoring systems that consistently measure $\mathrm{CO}_{2}$ flows. In recent years, several studies have addressed the issue of monitoring leakage flows to the atmosphere or affecting underground aquifers (Benson and Hepple, 2005; Dethlefsen et al., 2013). Monitoring seepage implies scanning a large area of land in proximity of storage sites, and there is not a consolidated or standardized approach yet, rather a number of research and demonstration projects (Jones et al., 2009; Etheridge et al., 2011; Romanak et al., 2012). Moreover, to guarantee an effective control on storage sites, the responsibilities and consequences of seepage must be clearly outlined, covered through appropriate regulation and, if applicable, covered under carbon pricing schemes (Imbus et al., 2013). Problems can arise when private companies or public institutions responsible for the injected $\mathrm{CO}_{2}$ do not monitor adequately, leading to undetected leakage. Considering the long term outlook, some regulations envisage a transition in responsibilities from private operators to governments after a certain number of years (e.g., 50 years) or in case of company closures. Furthermore, assuming leakage occurs and is correctly detected and measured, someone has to pay for local damages

\footnotetext{
${ }^{3}$ Note that these values are modeled leakage rates over the century and thus depend on the timing and deployment of CCS and carbon storage.

${ }^{4}$ These values per century are theoretical, meaning the amount of gas that would leak if it was all stored on the first year. The real leakage per century will depend on the intertemporal storage profile of the model, see Figure 2.
} 
and for the cost of global externality it is generating. In the case of a carbon pricing scheme, the latter cost is set by the carbon price. Also in this case, dodging responsibility by private or public authority would inhibit the economic benefits of CCS or CDR.

Not all countries have appropriate or specific regulation to address the safety and liability issue. Liu et al. (2016) provides a review of existing regulations in some developed countries and compares them with general Chinese environmental regulation. As an example, EU regulation establishes the payment for emissions credits in the Emissions Trading System (ETS) system for the storage operator (EU, 2009). Other useful measures are insulation of the perforation of the well, re-injection in more safe sites and insurance plans, also for companies that go bankrupt (Lackner and Brennan, 2009; Imbus et al., 2013). In conclusion, we have seen how important it is to assign responsibilities for monitoring and compensate leakage damages. Therefore, we included these aspects in this exercise, developing some scenarios that mimic successful or failed monitoring, pricing, and management of stored emissions.

\section{METHODOLOGY}

We use an integrated assessment model (IAM) to simulate the impact of leakage on the set of mitigation strategies. IAMs are tools which are routinely used to evaluate global climate policies. Currently, many integrated assessment models use aggregated storage cost and availability curves, notably the ones from Hendriks et al. (2004). For this exercise, we disaggregated the storage according to different types of storage including their respective potential and costs. Moreover, transportation costs also vary according to the storage site considered. Finally, we added leakage from the different storage sites and assessed a set of scenarios capturing different climate policies, leakage rates, and options to consider leaked carbon emissions. We use the WITCH (World Induced Technical Change Hybrid) integrated assessment model in this study.

WITCH is a global integrated assessment model with two main distinguishing features: a regional game-theoretic setup, and an endogenous treatment of technological innovation for energy conservation and decarbonization (Emmerling et al., 2016). A top-down inter-temporal Ramsey-type optimal growth model is hard linked with a representation of the energy sector described in a bottom-up fashion, hence the hybrid denomination. The regional and intertemporal dimensions of the model make it possible to differentiate and assess the optimal response to several climate and energy policies across regions and over time. The non-cooperative nature of international relationships is explicitly accounted for via an iterative algorithm which yields the open-loop Nash equilibrium between the simultaneous activity of a set of representative regions. Regional strategic actions interrelate through greenhouse gas (GHG) emissions, dependence on exhaustible natural resources, trade of fossil fuels and carbon permits, and technological research and development (R\&D) spillovers. R\&D investments are directed toward either energy efficiency improvements or development of carbon-free breakthrough technologies. Such innovation accumulates over time and spills across countries in the form of knowledge stocks and flows. R\&D investments, along with investments in energy technologies and the final goods sector, are endogenously determined in the intertemporal optimization. Within the energy sector, for new renewable energy sources (wind and solar), battery development, and advanced biofuels, learning is also taken into account through one or two factor learning curves, which determine future capital costs. The competition for land use between agriculture, forestry, and bioenergy, which are the main land-based production sectors, is described through a soft link with a land use and forestry model (GLOBIOM, Global Biosphere Management Model). A climate model (MAGICC) is used to compute climate variables from GHG emission levels, and an air pollution model (FASST) is linked to compute air pollutant concentrations.

Concerning CCS in the model, we consider four coal technology options (including the possibility of retrofitting existing plants), one gas and one biomass technology with carbon capture. The model includes seven types of storage (saline aquifers, EOR sites, depleted oil and gas fields, all either onshore or offshore, and onshore ECBM sites), each characterized by a maximum available capacity, a storage cost and an average distance from power plants. Apart from storage costs for the different types, all values are regionally differentiated. Finally, we account for an average specific transport cost dependent on the distance calibrated as $c_{t r}^{\prime}=0.006667 \$ / t \mathrm{CO}_{2} \mathrm{~km}$ (Rubin et al., 2015). The total cost of captured $\mathrm{CO}_{2}$ transport and storage $C_{t \& s}[\$ /$ year $]$ is therefore evaluated according to the following equation, where the dimensions are time $(t)$, regions $(n)$, and type of storage $\left(k_{s t}\right)$ :

$$
C_{t \& s}(t, n)=\sum_{k_{s t}} Q_{s t}\left(k_{s t}, n, t\right) \cdot\left(c_{t r}^{\prime} \cdot l_{t r}\left(n, k_{s t}\right)+c_{s t}\left(k_{s t}\right)\right)
$$

Here, $Q_{s t}\left[\mathrm{GtCO}_{2} /\right.$ year $]$ represents the yearly quantity of $\mathrm{CO}_{2}$ captured by CCS plants, $l_{t r}[\mathrm{~km}]$ represents the average distance, and $c_{s t}\left[\$ / t C \mathrm{C}_{2}\right]$ the storage cost. We consider an annual leakage rate $\lambda_{l k}$ of between $0.0 \% /$ year and up to $0.1 \% /$ year and include leaked emissions in the model. The cumulative amount of $\mathrm{CO}_{2}$ stored $\mathrm{CUM}_{\text {st }}\left[\mathrm{GtCO}_{2}\right]$ is therefore calculated based on annual stored values, considering that the model is run at a time step of 5 years, and including possible leakage every time period:

$$
\begin{aligned}
\operatorname{CUM}_{s t}\left(k_{s t}, n, t+1\right)= & \operatorname{CUM}_{s t}\left(k_{s t}, n, t\right) \cdot\left(1-\lambda_{l k}\left(k_{s t}, n, t\right)\right)^{5} \\
& +5 \cdot Q_{s t}\left(k_{s t}, n, t\right)
\end{aligned}
$$

Here, $\lambda_{l k}$ stands for the leakage rate, or the percentage of $\mathrm{CO}_{2}$ stored in the previous year that is lost due to leakage and emitted in the atmosphere. This set of equations allow us to represent the transport and storage chain as a single cost function, differentiated across regions. The cost function for each storage type follows a step increase in function of the cumulative stored quantity, where each step means a switch from a cheap but 
replete storage type to the immediate next, more expensive site. Finally, annual leaked emissions $Q_{\text {leak }}$ are computed as follows:

$$
Q_{\text {leak }}(n, t)=\sum_{k_{s t}} \lambda_{l k}\left(k_{s t}, n, t\right) \cdot C U M_{s t}\left(k_{s t}, n, t\right)
$$

It should be noted that $Q_{\text {leak }}$ in period $t$ is accounted for based on $C U M_{s t}$ in $t$, which is not including the emission captured in the same period, but only until $t-1$. This is to represent delay in leakage.

\section{SCENARIO DESIGN}

Based on this model implementation of storage, transportation, and leakage of $\mathrm{CO}_{2}$, we explore a set of 31 scenarios to capture the following dimensions: leakage rates, climate targets, and policy provisions. We implement different leakage rates (LR) starting from zero leakage, $0.01 \%, 0.05 \%$, and up to $0.1 \%$ per year.

Secondly, we consider different stringency of climate policies, represented by carbon budgets covering total $\mathrm{CO}_{2}$ emissions from fossil fuels and industrial processes from 2010 to 2100 . In addition to the business as usual (BAU) case without a future climate policy, we consider cases of 550, 1,000, and 1,600 GtCO corresponding to roughly $1.5,2.0$, and $2.5^{\circ} \mathrm{C}$ of global warming in 2100, according to the definition in the IPCC AR5 report (Edenhofer et al., 2014; Vuuren et al., 2017) ${ }^{5}$. When running these scenarios, the model sets a constraint on emitted $\mathrm{CO}_{2}$ equal to the budget and solves finding the cost optimal solution for attaining the target.

Finally, we differentiate the economic and policy treatment of carbon leakage emissions. In particular, we consider whether or not (a) leaked emissions are priced (through a carbon tax or the price of emission permits) or not, and (b) the leaked emissions are included in the carbon budget of the policy maker. Four cases are possible based on these distinctions: In the first case $(\mathrm{NN})$, leakage is not taken into account in the policy target nor priced, e.g., due to technical, institutional, or political barriers. This case allows us to assess the climatic impact of leakage if it is not taken into account for climate targets, nor in emission pricing schemes. The other limiting case, where pricing and monitoring are effective (YY), constitutes the first best case where the actual climate target is attained, and leakage is treated the same way as other carbon emissions and priced at the marginal cost of abatement. The two remaining cases represent different institutional, economic, and technological situations: In the YN case, leakage is anticipated for the climate policy goal, while due to monitoring or institutional constraints, the source cannot be taxed or held accountable. Hence, in this case, other mitigation options are required to counteract leakage emissions. Hypothetically, in the fourth situation (NY), on the other hand, pricing leakage emissions is possible and implemented, but the climate policy does not take leakage into account a situation which is not realistic and hence we do not consider it here.

\footnotetext{
${ }^{5}$ The IPCC AR5 Scenarios Database documents the long-term scenarios as reviewed in the Fifth Assessment Report (AR5) of Working Group III of the Intergovernmental Panel on Climate Change (IPCC) (Edenhofer et al., 2014).
}

TABLE 1 | Scenarios considered (31 in total).

\begin{tabular}{|c|c|c|}
\hline \multicolumn{3}{|c|}{$\begin{array}{l}\text { (A) THREE CASES REPRESENTING LEAKAGE MONITORING AND } \\
\text { LIABILITY }\end{array}$} \\
\hline \multirow{4}{*}{ 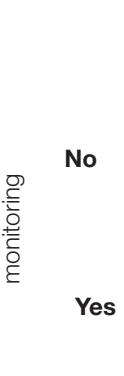 } & \multicolumn{2}{|r|}{ liability } \\
\hline & No & Yes \\
\hline & $\begin{array}{c}\text { NN } \\
\text { leakage not accounted } \\
\text { in carbon budget, nor } \\
\text { priced }\end{array}$ & [Not realistic] \\
\hline & $\begin{array}{c}\text { YN } \\
\text { leakage accounted in } \\
\text { carbon budget, but not } \\
\text { priced }\end{array}$ & $\begin{array}{c}\text { YY } \\
\text { leakage accounted in carbon } \\
\text { budget and correctly priced }\end{array}$ \\
\hline (B) BAU A & ND THREE CARBON & (C) FOUR LEAKAGE RATES \\
\hline \multicolumn{3}{|c|}{ BUDGETS [GtCO 2 BY 2100] } \\
\hline \multicolumn{2}{|c|}{ Climate target } & Leakage rate (\%/year) \\
\hline \multicolumn{2}{|l|}{ BAU } & $0.00 \%$ \\
\hline \multicolumn{2}{|l|}{1,600} & $0.01 \%$ \\
\hline \multicolumn{2}{|l|}{1,000} & $0.05 \%$ \\
\hline \multicolumn{2}{|l|}{550} & $0.10 \%$ \\
\hline
\end{tabular}

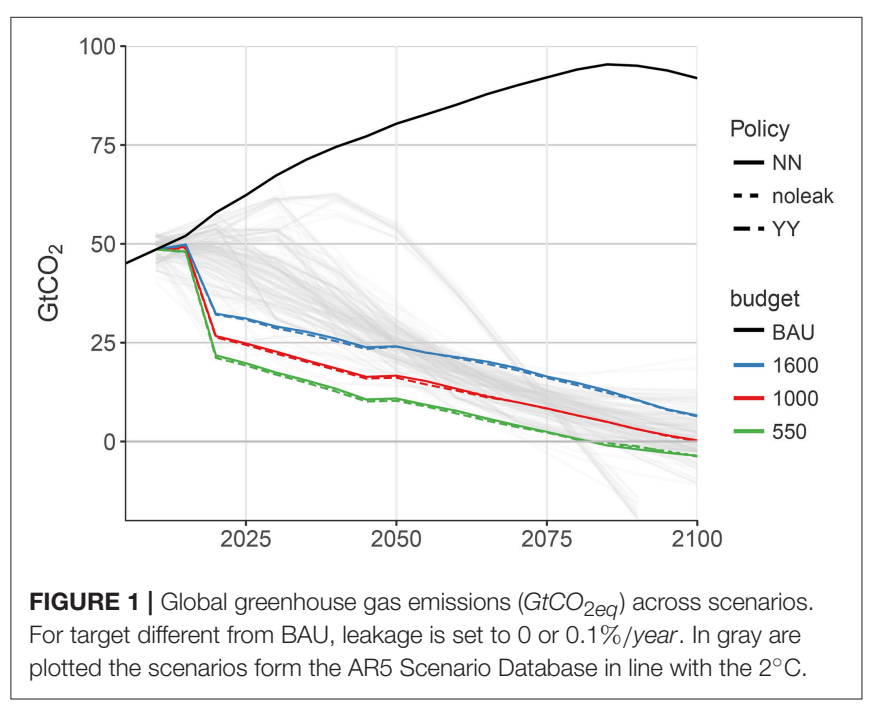

As summarized in Table 1, we consider three different policy prescriptions (NN, YN, YY) for three different carbon budgets $\left(1600,1000,550 \mathrm{GtCO}_{2}\right)$ and three leakage rates $(0.01,0.05,0.1$ $\% /$ year, total: 27 scenarios), in addition to the four scenarios without leakage (BAU, 1,600, 1,000, 550).

\section{RESULTS}

The different sets of scenarios show different patterns in terms of emissions, CCS deployment, and economic costs. Firstly, looking at overall greenhouse gas emissions, Figure 1 shows the no leakage and high leakage scenarios and compares them to the scenarios of the AR5 database that are consistent with the two degree target (Edenhofer et al., 2014). Overall, emissions 


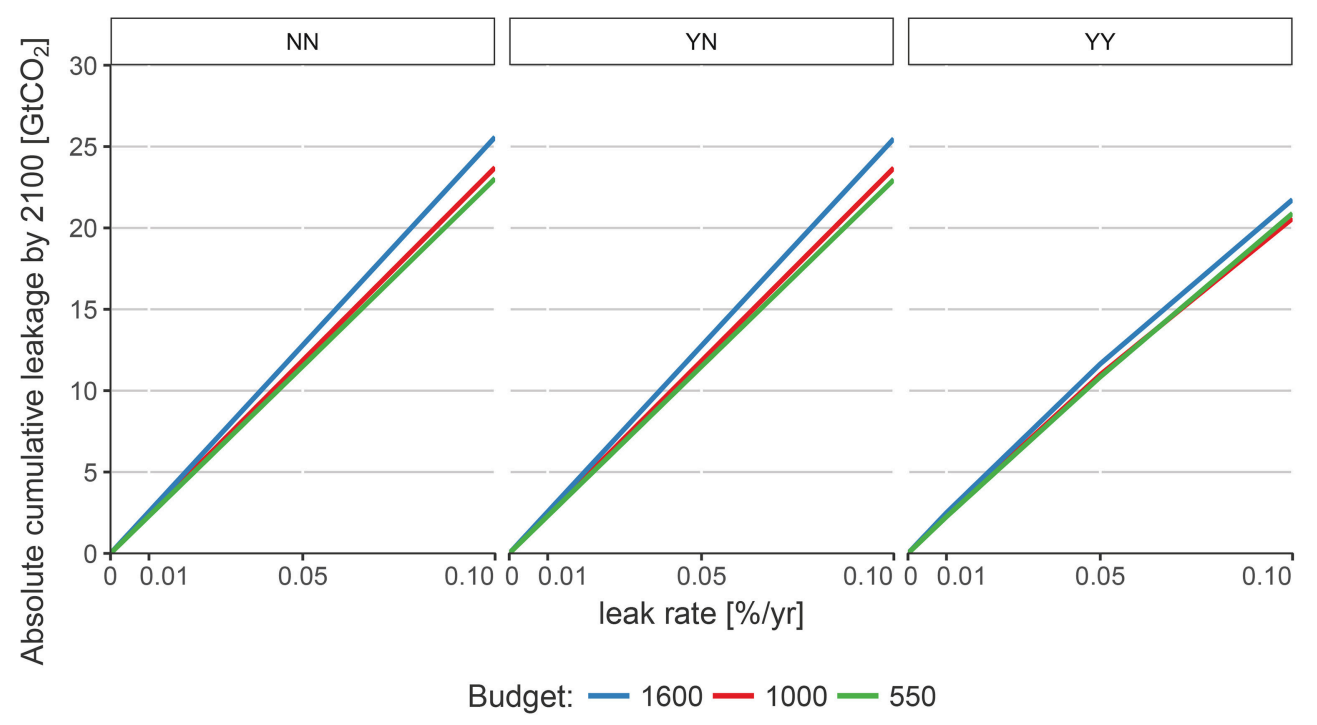

FIGURE 2 | Cumulative leaked emissions in the different scenarios [GtCO $]$. Captured emissions are around 700-750 GtCO for NN and YN scenarios and 650-700 $\mathrm{GtCO}_{2}$ for the $\mathrm{YY}$ scenario.

are only mildly affected by carbon leakage at the global scale, and the mitigation pathways are dominated by the stringency of the carbon budgets. In particular in the 550 scenarios, total emissions become negative toward the end of the century. The difference between cases where leakage (set as $0.1 \% /$ year of stored $\mathrm{CO}_{2}$ ) is well accounted for (YY) and when it is not $(\mathrm{NN})$ is small compared to total emissions, though still visible.

Looking closer at the leaked emissions, one can see that leakage can contribute to emissions as shown in Figure 2. The amount of leakage over this century in the $\mathrm{NN}$ and $\mathrm{YN}$ scenarios ranges from $2.5 \mathrm{GtCO}_{2}$ (for a leakage rate of $0.01 \% /$ year) to around $25 \mathrm{GtCO}_{2}$ for a leakage rate of $0.1 \% /$ year. Moreover, while it is quite similar for the different climate targets, it shows the highest values always for the 1,600 $\mathrm{GtCO}_{2}$ scenario, where fossil-based CCS is widely deployed. Comparing the leakage to the amount of captured emissions for the $\mathrm{NN}$ and YN scenarios (around 700-750 GtCO 2 ), we get around $0.5 \%$ of leakage until 2100 for the low leakage rate, and $3 \%$ for the high leakage rate cases. These values are virtually unchanged in the YN and NN scenarios, where leakage is not priced and hence does not affect CCS deployment. However, in the YY scenario, when the effect and cost of leakage are fully accounted for, the model responds with a reduction in leakage, linked to a reduction in CCS technology adoption and captured emissions. For the highest leakage rate of $0.1 \%$, captured emissions are lowered by about 5-10 GtCO $\mathrm{O}_{2}$ across the different climate targets. The percentage of leaked emission on the total captured between 2015 and 2100 is however similar to the previous scenarios. If compared to Deng et al. (2017), our results show higher percentage of emission leaking over the century given similar leakage rates. This is due to their assumption that most of leaked emissions do not reach the surface, but are priced and thus have a negative impact on CCS deployment.

Leaked emissions have an impact on the climate, in terms of $\mathrm{CO}_{2}$ concentrations and global temperature increase, shown in Figure 3. In absolute terms, variations in global mean temperature increase in 2100 are relatively small, of the order of magnitude of $0.01{ }^{\circ} \mathrm{C}$ when leaked emissions are not monitored. For the $\mathrm{YN}$ and $\mathrm{YY}$ scenarios where leakage is accounted in the carbon budget target, the results show a small temperature decrease with increasing leakage rate. This can be explained due to different timing of emissions, notably due to the early shift to zero carbon technologies replacing CCS. While overall the temperature effect is relatively small, it still implies further exacerbation of global warming when leakage is not accounted in the budget, which might be relevant for the most stringent scenarios.

Figure 4 shows that the reduction in CCS (in terms of capacity reduction by 2100) is linked to the leakage rate, and to whether it is priced and accounted for in the carbon budget: only in the case where the costs of leaked emissions are accounted for in the economy through carbon pricing (YY) is CCS substantially reduced. Therefore, in the scenarios where countries do not pay for their leaked emission, CCS is not affected, both in the case where seepage is considered in the carbon budget or not (YN and $\mathrm{NN}$ scenarios). This result can be explaind since leakage can not be directly linked to the storage owners and the capturing power plant. The CCS reduction is particularly high for fossil fuel based CCS where the reduction reaches between 10 and up to 35 per cent of the capacity without leakage. Bio-energy with carbon capture and storage (BECCS), on the other hand, shows reductions lower than $10 \%$. That is, for biomass CCS, leakage seems to provide a less important barrier, even with a leakage 


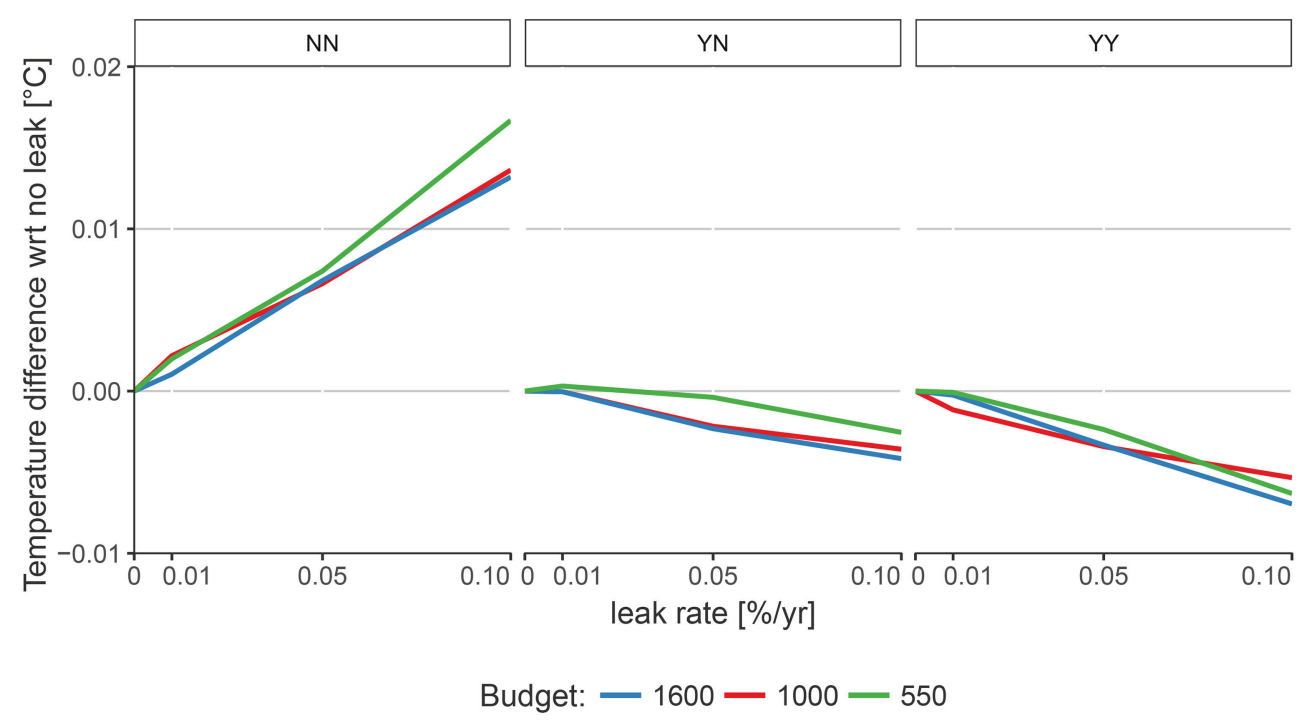

FIGURE 3 | Global mean temperature increase compared to no leakage case $\left[{ }^{\circ} \mathrm{C}\right]$.

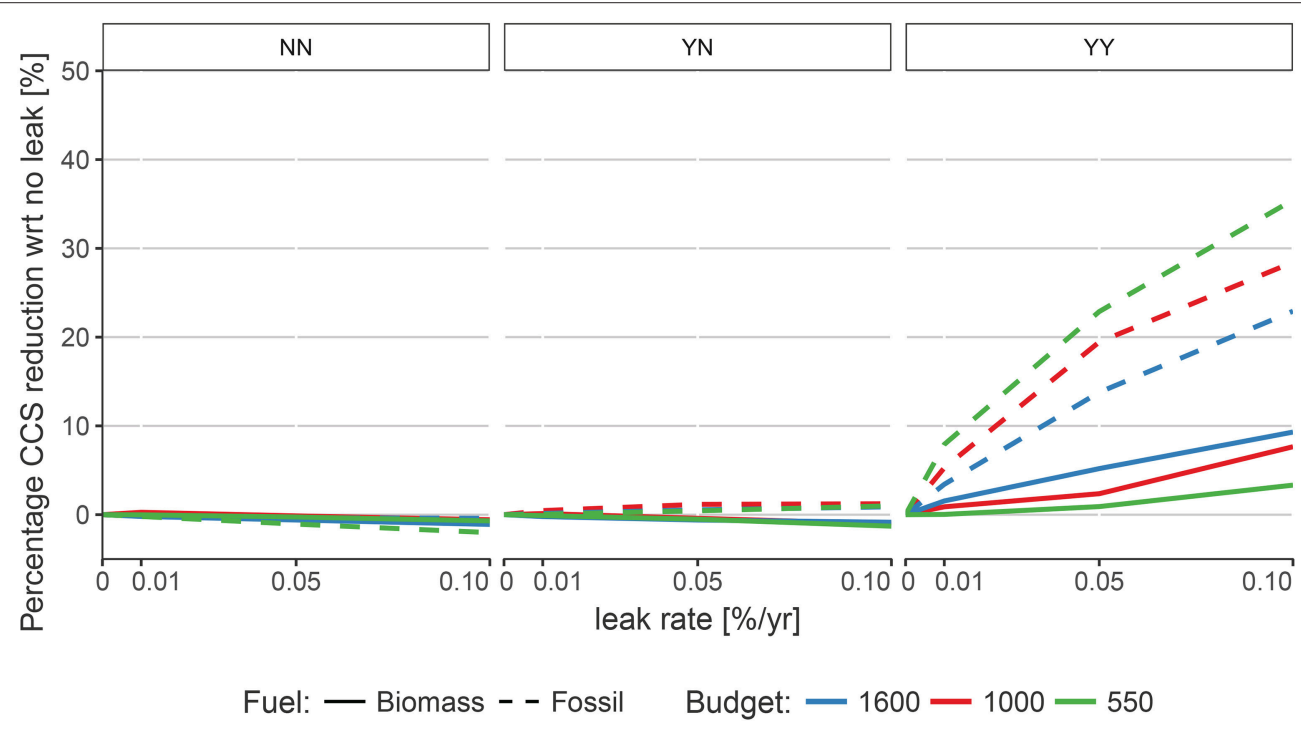

FIGURE 4 | Capacity reduction in CCS compared to no leakage case [\%]. The reference values of total installed capacity by 2100 in case of zero leakage are: 61 TW (biomass) and 52 TW (fossil) for the 1,600 scenario, 63 TW (bio) and $37 \mathrm{TW}$ (fossil) for 1,000 GtCO 2 and 75 TW (bio) and 25 TW (fossil) in the 550 GtCO 2 case.

rate of $0.1 \%$ per year, especially in the most stringent $1.5^{\circ} \mathrm{C}$ scenario. Moreover, it is interesting to note that the ordering across stringency of the climate targets is reversed for fossil fuel and biomass based CCS: The more stringent the scenario considered, the lower the impact on BECCS and the higher the reduction of fossil based CCS. This result is in line with the intermediary role of fossil fuel based CCS found e.g., in Rogelj et al. (2015), van der Zwaan and Smekens (2009) and Deng et al. (2017), even if these two latter studies did not consider stringent scenario such as the $1.5^{\circ} \mathrm{C}\left(550 \mathrm{GtCO}_{2}\right)$.

In terms of economic costs of carbon leakage, we first look at the implied carbon price required to meet the different climate targets. Figure 5 shows the increase in carbon price with respect to the no leakage cases, noticeable for scenarios where leakage is included in the carbon budget. The standard carbon prices in the three scenarios in the year 2020 to implement the carbon budgets of $1,600,1,000$, and $550 \mathrm{GtCO}_{2}$ are 79,164 , and $318 \$ / t \mathrm{CO}_{2 e q}$ respectively, and grow at a rate of $5 \%$ per year 6 . Comparing to these default scenarios the leakage cases, first note that the NN scenario does not show any change in the carbon price as leakage increases, since it is not considered for the policy

${ }^{6}$ Note that therefore the relative difference in carbon prices shown in Figure 5 are constant over time and across regions. 


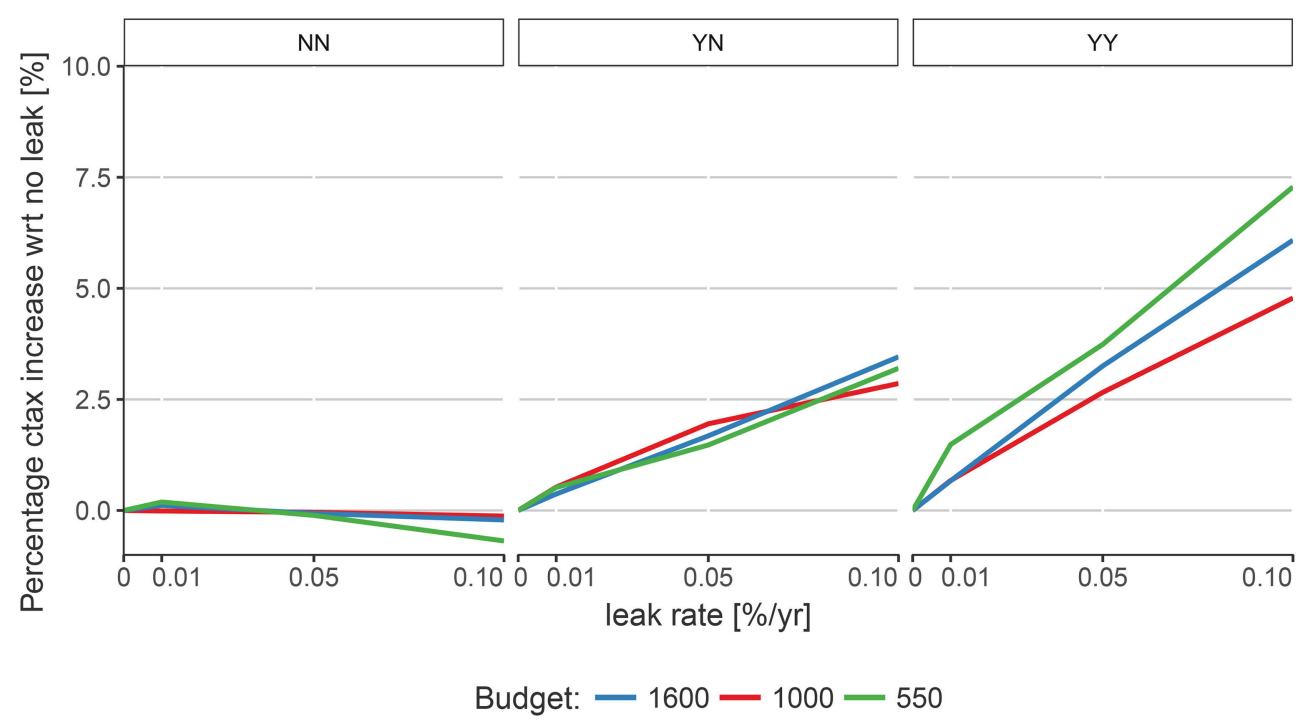

FIGURE 5 | Relative increase of the carbon price compared to no leakage case [\%]. The carbon prices in 2,020 for 1,600, 1,000, and 550 GtCO 2 (no leakage case) are 79,164 , and $318 \$ / \mathrm{tCO}_{2 e q}$ respectively.

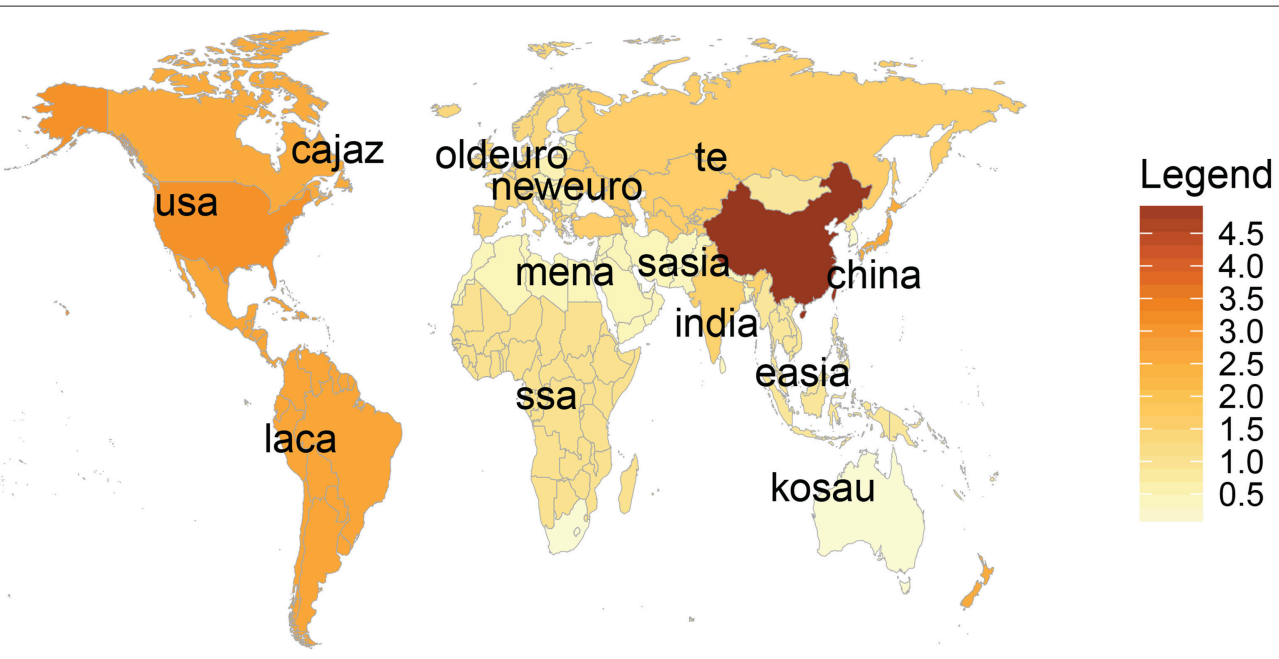

FIGURE 6 | Cumulative leaked emissions by 2100 in the scenario 550, NN and leakage rate of $0.1 \% /$ year [GtCO $]$.

design. When seepage affects the carbon budget available for each climate policy, it becomes necessary to mitigate this effect using other technological strategies more expensive than CCS. This results in an increase of carbon price in the YN and YY scenarios, which ranges from 2.5 to $7.5 \%$. When leakage is not priced (YN), it still leads to a higher carbon price due to the reduced global carbon budget, albeit to a lesser extent, resulting from higher mitigation effort based on the most cost-effective mitigation options available. When it is also priced, the costeffective potential of CCS is significantly reduced, resulting in higher use of more expensive mitigation options such as energy efficiency improvements or renewable energy sources. Across carbon budgets, it should be noted that, although the relative variation in the carbon tax is similar, in absolute value it differs significantly.

The previous results showed how uncontrolled seepage would affect global climate and how, even well monitored leakage might be binding for CCS development and would lead, globally, to a more expensive energy system. Now we focus on the regionally differentiated modeling results, focusing here on the most stringent scenario (550) and using the $0.1 \%$ leakage rate, while for smaller rates the results scale down almost linearly as shown before.

As shown in Figure 6, the cumulative leaked emissions are not evenly distributed across regions: China, the United States, Canada/Japan (cajaz), and Latin America (laca) countries are 
expected to extensively use CCS power plants, and therefore are projected to leak more than $2 \mathrm{GtCO}_{2}$, with China reaching 5 $\mathrm{GtCO}_{2}$ by 2100 (see Table 2 for the description of the regions).

Given the relatively high carbon price required to achieve the stringent climate policy targets, leakage can imply substantial additional costs of emissions, according to the carbon price in place. In the aforementioned regions with high projected leakage potential, this amounts to values between 75 and 200 billion USD over the century, with exception of 550 billion for China, see the left panel in Figure 7 (all values reported there refer to NPV cumulative values from 2015 to 2100, discounted at a $5 \%$ discount rate). In the scenario 550, NN with high leakage, the (discounted) yearly value of leaked emissions in 2100 reaches up to 12 billion USD in China and about 7 billion USD in Latin America. Globally, the yearly leakage in 2100 of $0.78 \mathrm{GtCO}_{2}$ amounts to a discounted value of 54 billion USD. Given the relatively small carbon budget consistent with the 1.5 degree scenario, the additional $25 \mathrm{GtCO}_{2}$ of leaked carbon

TABLE 2 | Regions of the WITCH model.

\begin{tabular}{ll}
\hline WITCH region & Description \\
\hline usa & United States of America \\
oldeuro & Western Europe (EU15+EFTA) \\
neweuro & Eastern Europe (EU12+European EITs excluding FSU countries) \\
kosau & South Korea, South Africa, Australia \\
cajaz & Canada, Japan, New Zealand \\
te & Non-EU Eastern European countries, including Russia \\
mena & Middle East and North Africa \\
ssa & Sub Saharan Africa \\
sasia & South Asia (except India) \\
china & China, including Taiwan \\
easia & South East Asia, including Indonesia \\
laca & Latin America, Mexico and Caribbean \\
india & India
\end{tabular}

emissions associated with the high leakage rate $(0.1 \% /$ year $)$ scenario represent a significant cost, with particular economic implications for some regions. Moreover, we can compare which regions have to bear the additional costs if, while initially not being priced, now leaked emissions are accordingly priced and the climate target is the same, i.e., moving from scenario $\mathrm{YN}$ to YY. The right part of Figure 7 shows the additional cost of leakage emissions when they are priced at the global carbon price (YY) compared to the case where they are not (YN): almost all regions show a negative difference, meaning that they reduce expenses when leakage is well regulated. In Canada/Japan (cajaz), including the leakage costs in the economy does not lead to a large CCS reduction. Therefore, the higher carbon price in the YY scenario results in higher costs for the country. This occurs mainly because the use of BECCS late in the century seems essential for these countries. In countries where CCS is only marginally profitable, its optimal deployment is reduced facing leakage, and hence the required carbon price is slightly higher, while leakage is significantly reduced. Since the latter effect dominates, those countries gain in terms of the value of carbon.

These are the value of losses that would not be payed by companies or countries in absence of regulation. But they can also be seen as a waste of money for a country which is investing in climate mitigation policies, and the cost of reabating leaked emission. Moreover, other costs, like local or climate change damages are not accounted in this estimation, therefore the real economic loss might be even higher. Note that in both cases the carbon price increases with leakage rate, as more expensive low carbon technologies are installed to compensate seepage. However the YY scenario represents a perfect regulation system where CCS owners pay for the leaked emissions, so that use of CCS is reduced and the carbon price increases further. This behavior is considered more convenient than continuing using CCS and paying for leakage. The difference in total leakage costs can be considered as the regional gain or loss if leakage is well regulated or not. Moreover, we also compare the GDP of all scenarios to
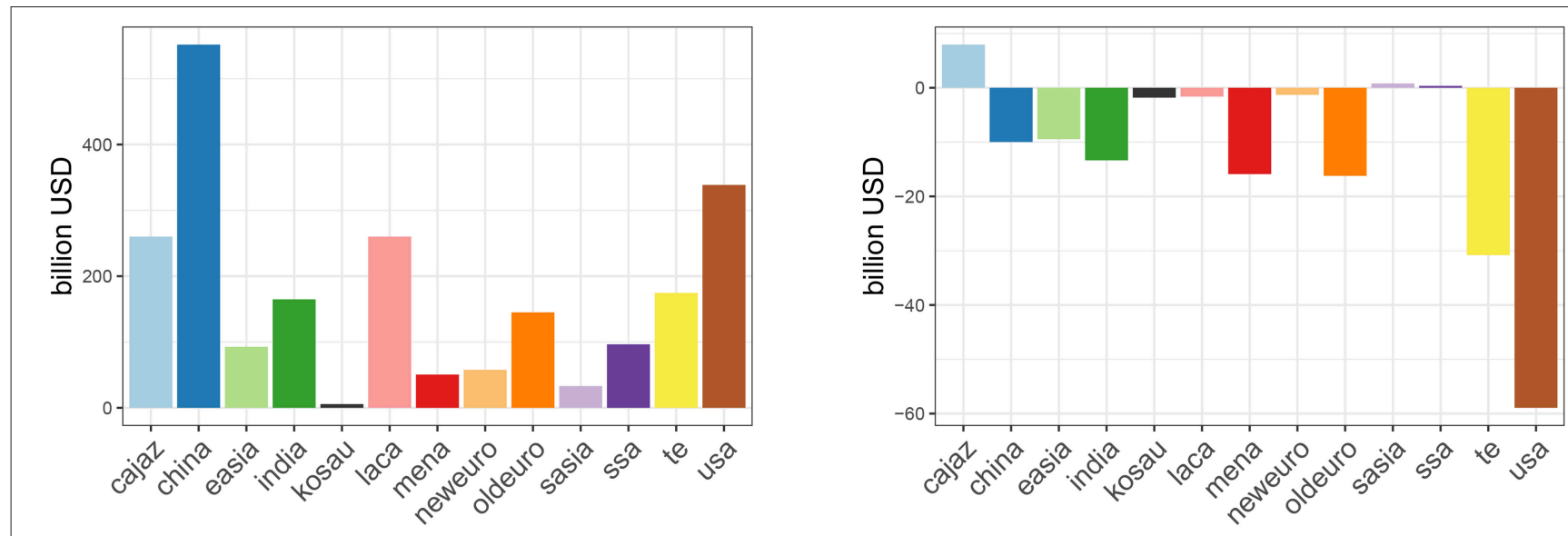

FIGURE 7 | Total value of leaked emission by 2100 in scenario 550 with leakage rate of $0.1 \% /$ year (NN, left), and difference when priced (between $Y Y$ and $Y N$, right). 
TABLE 3 | Policy Cost with respect to BAU for different leakage rates and pricing policies [\% of GDP].

\begin{tabular}{|c|c|c|c|c|c|c|c|}
\hline \multirow{2}{*}{$\begin{array}{l}\text { Leakage rate } \\
\text { CB\policy }\end{array}$} & \multirow[t]{2}{*}{0} & \multicolumn{2}{|c|}{$0.01 \% /$ year } & \multicolumn{2}{|c|}{$0.05 \% /$ year } & \multicolumn{2}{|c|}{$0.1 \% /$ year } \\
\hline & & YN & YY & YN & YY & YN & YY \\
\hline 1,600 & 3.38 & 3.39 & 3.40 & 3.42 & 3.47 & 3.46 & 3.54 \\
\hline 1,000 & 5.64 & 5.66 & 5.68 & 5.72 & 5.75 & 5.77 & 5.86 \\
\hline 550 & 8.52 & 8.53 & 8.55 & 8.56 & 8.68 & 8.64 & 8.86 \\
\hline
\end{tabular}

analyze the changes in policy costs with respect to the BAU scenario. Table 3 reports the policy cost for the aforementioned scenarios. We confirm the above mentioned trend of policy $\operatorname{cost}^{7}$ increasing with leakage rate and from zero leakage case to YY setting. Overall, policy costs increase in the range of $0.1-0.2 \%$ in the $\mathrm{YN}$ case due to the higher mitigation effort needed. If moreover leakage is priced, they increase by a further 0.1-0.2 percentage points. For instance, in the stringent 550, YY scenario and for a leakage rate of $0.1 \%$, the costs of staying below $1.5^{\circ}$ increase from $8.5 \%$ to almost $8.9 \%$ due to leakage.

\section{CONCLUSION}

The purpose of this work is to expand the assessment of leakage impact on CCS deployment and climate policies. We consider different institutional and economic settings reproducing issues in monitoring and paying for possible leakage. Furthermore, we perform analysis over leakage rates, and over three different climate scenarios, including the 1.5 and $2^{\circ} \mathrm{C}$ temperature increase

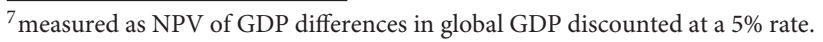

\section{REFERENCES}

Benson, S., and Hepple, R. (2005). "Detection and options for remediation of leakage from underground $\mathrm{CO}_{2}$ storage projects," in Greenhouse Gas Control Technologies (Vancouver, BC).

Benson, S. M. K., Bennaceur, P., Cook, J., Davison, H., de Coninck, K., Farhat, A., et al. (2012). "Chapter 13-carbon capture and storage," in Global Energy Assessment-Toward a Sustainable Future (Cambridge, UK; New York, NY: Cambridge University Press; Laxenburg: International Institute for Applied Systems Analysis), 993-1068.

Bielicki, J. M., Peters, C. A., Fitts, J. P., and Wilson, E. J. (2015). An examination of geologic carbon sequestration policies in the context of leakage potential. Int. J. Greenhouse Gas Control 37, 61-75. doi: 10.1016/j.ijggc.2015.02.023

Bielicki, J. M., Pollak, M. F., Deng, H., Wilson, E. J., Fitts, J. P., and Peters, C. A. (2016). The leakage risk monetization model for geologic $\mathrm{CO}_{2}$ storage. Environ. Sci. Technol. 50, 4923-4931. doi: 10.1021/acs.est.5b05329

Celia, M. A., Bachu, S., Nordbotten, J. M., and Bandilla, K. W. (2015). Status of $\mathrm{CO}_{2}$ storage in deep saline aquifers with emphasis on modeling approaches and practical simulations. Water Resour. Res. 51, 6846-6892. doi: 10.1002/2015WR017609

Cole, I. S., Corrigan, P., Sim, S., and Birbilis, N. (2011). Corrosion of pipelines used for $\mathrm{CO}_{2}$ transport in CCS: is it a real problem? Int. J. Greenhouse Gas Control 5, 749-756. doi: 10.1016/j.ijggc.2011.05.010

Davidson, C. L., Dahowski, R. T., McJeon, H. C., Clarke, L. E., Iyer, G. C., and Muratori, M. (2017). The value of CCS under current target by 2100 , particularly relevant after the Paris agreement in 2015. The results show that carbon leakage can lead to up to $25 \mathrm{GtCO}_{2}$ of additional emissions throughout the twenty-first century for a leakage rate of $0.1 \%$ per year, which represents about $3 \%$ of total captured emissions. Considering a more optimistic leakage rate $(0.01 \%)$, only $0.5 \%$ of injected emissions would leak by 2100 . If accounted for in the carbon budget and priced, CCS deployment is expected to be lowered by up to $35 \%$ (fossil) and $10 \%$ (BECCS) for high leakage rates. This means that CCS remains an important technology for mitigation in the power sector, notably coal and gas based in less stringent scenarios, and biomass fueled for the $1.5^{\circ} \mathrm{C}$ scenario. Due to more earlyon abatement, considering leakage leads to slightly lower global warming in the long run. If not taken into consideration nor priced, on the other hand, it leads to an around 0.01-0.02 degrees higher global mean temperature. Overall, policy costs increase by about $0.2-0.4$ percentage points (of GDP loss) due to considered leakage. In terms of regional distribution, China, Latin America, the U.S., and Canada have the highest leakage amount to be expected by 2100 . The associated economic value of this quantity ranges across regions from 70 to more than 200 billion USD. Finally, we demonstrated how appropriate monitoring and accounting of leakage imply a reduction in use of CCS and also economic saving for most countries.

\section{AUTHOR CONTRIBUTIONS}

AV contributed to developing the idea, methodology, model design and execution, writing and revising the manuscript; JE contributed to developing the idea and methodology, supervised model design and execution, writing and revising the manuscript; MT have supervised the work, providing suggestions on the research scope and revisions.

policy scenarios: NDCs and beyond. Energy Procedia 114, 7521-7527. doi: 10.1016/j.egypro.2017.03.1885

Deng, H., Bielicki, J. M., Oppenheimer, M., Fitts, J. P., and Peters, C. A. (2017). Leakage risks of geologic $\mathrm{CO}_{2}$ storage and the impacts on the global energy system and climate change mitigation. Clim. Change 144, 151-163. doi: 10.1007/s10584-017-2035-8

Dethlefsen, F., Köber, R., Schäfer, D., Hagrey, S. A. A., Hornbruch, G., Ebert, M., et al. (2013). Monitoring approaches for detecting and evaluating $\mathrm{CO}_{2}$ and formation water leakages into near-surface aquifers. Energy Procedia 37(Suppl. C), 4886-4893. doi: 10.1016/j.egypro.2013. 06.399

Dooley, J. J. (2013). Estimating the supply and demand for deep geologic $\mathrm{CO}_{2}$ storage capacity over the course of the 21st century: a meta-analysis of the literature. Energy Procedia 37, 5141-5150. doi: 10.1016/j.egypro.2013.06.429

Edenhofer, O., Pichs-Madruga, R., Sokona, Y., Farahani, E., Kadner, S., Seyboth, K., et al. (2014). Climate Change 2014: Mitigation of Climate Change: Contribution of Working Group iii to the Fifth Assessment Report of the Intergovernmental Panel on Climate Change. Cambridge, UK; New York, NY: Cambridge University Press..

Emmerling, J., Drouet, L., Reis, L. A., Bevione, M., Berger, L., Bosetti, V., et al. (2016). "The WITCH 2016 Model-Documentation and Implementation of the Shared Socioeconomic Pathways," in Working Paper 2016.42. Milan: Fondazione Eni Enrico Mattei.

Etheridge, D., Luhar, A., Loh, Z., Leuning, R., Spencer, D., Steele, P., et al. (2011). Atmospheric monitoring of the $\mathrm{CO}_{2} \mathrm{crc}$ Otway project and 
lessons for large scale $\mathrm{CO}_{2}$ storage projects. Energy Procedia 4, 3666-3675. doi: 10.1016/j.egypro.2011.02.298

EU, C. (2009). Directive 2009/31/EC of the European Parliament and of the Council of 23 April 2009 on the geological storage of carbon dioxide and amending Council Directive 85/337/EEC, European Parliament and Council Directives 2000/60/EC, 2001/80/EC, 2004/35/EC, 2006/12/EC, 2008/1/EC and Regulation (EC) No 1013/2006. Technical report, European Union.

Finkenrath, M. (2011). "Cost and performance of carbon dioxide capture from power generation,” in IEA Energy Papers 2011/5. Paris: International Energy Agency.

Gale, J. J. (2004). Using coal seams for $\mathrm{CO}_{2}$ sequestration. Geol. Belgica 7, 99-103. Available online at: https://popups.uliege.be:443/1374-8505/index.php?id=239

GCCSI (2011). Accelerating the Uptake of CCS: Industrial use of Captured Carbon Dioxide. Technical report, Global Carbon Capture and Storage Institute.

GCCSI (2014). What Happens When $\mathrm{CO}_{2}$ is Stored Underground? qea From the IEAGHG Weyburn-Midale $\mathrm{CO}_{2}$ Monitoring and Storage Project. Technical report, Global CCS Institute (Docklands, VIC).

GCCSI (2016). The Global Status of CCS 2016: Summary Report. Technical report, Global Carbon Capture and Storage Institute.

Godec, M., Kuuskraa, V., Van Leeuwen, T., Stephen Melzer, L., and Wildgust, N. (2011). $\mathrm{CO}_{2}$ storage in depleted oil fields: the worldwide potential for carbon dioxide enhanced oil recovery. Energy Procedia 4, 2162-2169. doi: 10.1016/j.egypro.2011.02.102

Hendriks, C., Graus, W., and van Bergen, F. (2004). Global Carbon Dioxide Storage Potential and Costs. Technical report, Ecofys.

IEA (2008). $\mathrm{CO}_{2}$ Capture and Storage: A Key Carbon Abatement Option. Technical report, International Energy Agency (Paris).

IEA (2015). Insight Publications: Storing $\mathrm{CO}_{2}$ Through Enhanced Oil Recovery. Technical report, International Energy Agency (Paris).

IEA (2016). 20 Years of Carbon Capture and Storage-Accelerating Future Deployment. Technical report, International Energy Agency (Paris).

IEA-ETSAP (2010). $\mathrm{CO}_{2}$ Capture and Storage. Technical report, IEA Energy Technology Systems Analysis (Paris).

IEAGHG (2008). Aquifer Storage: Development Issues. Camberra: IEA Greenhouse Gas R\&D Programme. Available online at: http://www.globalccsinstitute.com/ publications/aquifer-storage-development-issues

IEAGHG (2011). Potential for Biomass and Carbon Dioxide Capture and Storage. Technical report, IEA Greenhouse Gas R\&D Programme (Cheltenham). Camberra. Available online at: http://www.globalccsinstitute. com/publications/aquifer-storage-development-issues

IEAGHG (2016). Can $\mathrm{CO}_{2}$ capture and storage unlock 'unburneable carbon'? Technical report, IEA Greenhouse Gas R\&D Programme, (Cheltenham).

Imbus, S. W., Dodds, K., Otto, C. J., Trautz, R. C., Christopher, C. A., Agarwal, A., et al. (2013). $\mathrm{CO}_{2}$ storage contingencies initiative: detection, intervention and remediation of unexpected $\mathrm{CO}_{2}$ migration. Energy Procedia 37(Suppl. C), 7802-7814. doi: 10.1016/j.egypro.2013.06.343

IPCC (2014). CLIMATE CHANGE 2014 Mitigation of Climate Change. Technical report, Intergovernmental Panel on Climate Change.

Jones, D. G., Barlow, T., Beaubien, S. E., Ciotoli, G., Lister, T. R., Lombardi, S., et al. (2009). New and established techniques for surface gas monitoring at onshore CO2 storage sites. Energy Procedia 1, 2127-2134. doi: 10.1016/j.egypro.2009.01.277

Koelbl, B. S., van den Broek, M., van Ruijven, B., Faaij, A. P. C., and van Vuuren, D. P. (2014). Uncertainty in the deployment of Carbon Capture and Storage (CCS): a sensitivity analysis to techno-economic parameter uncertainty. Int. J. Greenhouse Gas Control 27, 81-102. doi: 10.1016/j.ijggc.2014.04.024

Koelbl, B. S., van den Broek, M., van Ruijven, B., van Vuuren, D. P., and Faaij, A. P. C. (2013). A sensitivity analysis of the global deployment of CCS to the cost of storage and storage capacity estimates. Energy Procedia 37, 7537-7544. doi: 10.1016/j.egypro.2013.06.697

Lackner, K. S., and Brennan, S. (2009). Envisioning carbon capture and storage: expanded possibilities due to air capture, leakage insurance, and C-14 monitoring. Clim. Change 96, 357-378. doi: 10.1007/s10584-009-9632-0
Lipponen, J., McCulloch, S., Keeling, S., Stanley, T., Berghout, N., and Berly, T. (2017). The politics of large-scale CCS deployment. Energy Procedia 114, 7581-7595. doi: 10.1016/j.egypro.2017.03.1890

Little, M. G., and Jackson, R. B. (2010). Potential impacts of leakage from deep $\mathrm{CO}_{2}$ geosequestration on overlying freshwater aquifers. Environ. Sci. Technol. 44, 9225-9232. doi: 10.1021/es102235w

Liu, L.-C., Li, Q., Zhang, J.-T., and Cao, D. (2016). Toward a framework of environmental risk management for $\mathrm{CO}_{2}$ geological storage in china: gaps and suggestions for future regulations. Mitigat. Adapt. Strateg. Global Change 21, 191-207. doi: 10.1007/s11027-014-9589-9

McCoy, S. T., and Rubin, E. S. (2008). An engineering-economic model of pipeline transport of $\mathrm{CO} 2$ with application to carbon capture and storage. Int. J. Greenhouse Gas Control 2, 219-229. doi: 10.1016/S1750-5836(07)00119-3

Metz, B., Davidson, O., de Coninck, H., Loos, M., and Meyer, L. (2005). IPCC-Carbon Dioxide Capture and Storage (SRCCS). Technical report, Intergovernmental Panel on Climate Change.

NAS (2015). Climate Intervention: Carbon Dioxide Removal and Reliable Sequestration. Technical report, National Research Council (U.S.), National Academies Press.

Rogelj, J., Luderer, G., Pietzcker, R. C., Kriegler, E., Schaeffer, M., Krey, V., et al. (2015). Energy system transformations for limiting end-of-century warming to below 1.5c. Nat. Clim. Change 5, 519-527. doi: 10.1038/nclimate2572

Romanak, K. D., Bennett, P. C., Yang, C., and Hovorka, S. D. (2012). Process-based approach to $\mathrm{CO}_{2}$ leakage detection by vadose zone gas monitoring at geologic $\mathrm{CO}_{2}$ storage sites. Geophys. Res. Lett. 39:L15405. doi: 10.1029/2012GL052426

Romanov, V., Soong, Y., Carney, C., Rush, G. E., Nielsen, B., and O’Connor, W. (2015). Mineralization of carbon dioxide: a literature review. ChemBioEng Rev. 2, 231-256. doi: 10.1002/cben.201500002

Rubin, E. S., Davison, J. E., and Herzog, H. J. (2015). The cost of $\mathrm{CO}_{2}$ capture and storage. Int. J. Greenhouse Gas Control 40, 378-400. doi: 10.1016/j.ijggc.2015.05.018

Sanna, A., Uibu, M., Caramanna, G., Kuusik, R., and Maroto-Valer, M. (2014). A review of mineral carbonation technologies to sequester $\mathrm{CO}_{2}$. Chem. Soc. Rev. 43, 8049-8080. doi: 10.1039/C4CS00035H

van der Zwaan, B., and Gerlagh, R. (2009a). Economics of geological $\mathrm{CO}_{2}$ storage and leakage. Clim. Change 93, 285-309. doi: 10.1007/s10584-009-9558-6

van der Zwaan, B., and Gerlagh, R. (2009b). Effectiveness of CCS with time-dependent $\mathrm{CO}_{2}$ leakage. Energy Procedia 1, 4977-4984. doi: 10.1016/j.egypro.2009.05.002

van der Zwaan, B., and Smekens, K. (2009). $\mathrm{CO}_{2}$ capture and storage with leakage in an energy-climate model. Environ. Model. Assess. 14, 135-148. doi: 10.1007/s10666-007-9125-3

Vuuren, D. P. v., Hof, A., Gernaat, D., and de Boer, H. S. (2017). Limiting Global Temperature Change to $1.5^{\circ} \mathrm{C}$. PBL Netherlands Environmental Assessment Agency Report.

Wilson, E. J., Johnson, T. L., and Keith, D. W. (2003). Regulating the ultimate sink: managing the risks of geologic $\mathrm{CO}_{2}$ storage. Environ. Sci. Technol. 37, 3476-3483. doi: 10.1021/es021038+

ZEP (2011). The Costs of $\mathrm{CO}_{2}$ Capture, Transport and Storage. Technical report, European Technology Platform for Zero Emission Fossil Fuel Power Plants (Brussels).

Conflict of Interest Statement: The authors declare that the research was conducted in the absence of any commercial or financial relationships that could be construed as a potential conflict of interest.

Copyright (c) 2018 Vinca, Emmerling and Tavoni. This is an open-access article distributed under the terms of the Creative Commons Attribution License (CC $B Y)$. The use, distribution or reproduction in other forums is permitted, provided the original author(s) and the copyright owner are credited and that the original publication in this journal is cited, in accordance with accepted academic practice. No use, distribution or reproduction is permitted which does not comply with these terms. 